Corresponding Author:

Mohamed Salih Mahfouz;

email:

mm.mahfouz@gmail.com

Received: 28 December 2019

Accepted: 10 March 2020

Published: 30 April 2020

Production and Hosting by Knowledge E

(c) Fatima Awad Elkarim Elfaki et al. This article is distributed under the terms of the

Creative Commons

Attribution License, which

permits unrestricted use and redistribution provided that the original author and source are credited.

Editor-in-Chief:

Dr. Dimitrios Papandreou

Official Publication of Zayed University, UAE

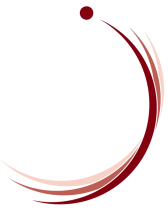

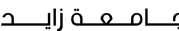
ZAYED UNIVERSITY

G OPEN ACCESS

\section{Effect of Healthy Lifestyle Interventions in Schools of Jazan City, Kingdom of Saudi Arabia: A Quasi-experimental Study}

\section{Fatima Awad Elkarim Elfaki ${ }^{1}$, Husam Eldin Elsawi Khalafalla ${ }^{2}$, Abdelrahim Mutwakel Gaffar ${ }^{3,4}$, Mohamed E Moukhyer ${ }^{5}$, Ibrahim A Bani ${ }^{6,7}$, and Mohamed Salih Mahfouz ${ }^{2}$}

${ }^{1}$ Department of Clinical Nutrition, College of Applied Medical Sciences, Jazan University, Jizan, KSA

${ }^{2}$ Department of Family and Community Medicine, Faculty of Medicine, Jazan University, Jizan, KSA

${ }^{3}$ Nahda College, Khartoum, Sudan

${ }^{4}$ College of Health and Human Services, George Mason University, USA

${ }^{5}$ Department of Academic Development and Quality, Faculty of Applied Medical Sciences, Jazan University, Jizan, KSA

${ }^{6}$ Rollins School of Public Health, Emory University, Atlanta GA, USA

${ }^{7}$ Department of Community Medicine and Health Care, Faculty of Medicine Alqunfudah, Umm Algura University, KSA

\section{Abstract}

Background: Unhealthy dietary habits and lifestyle among adolescents is considered as a risk factor for nutrition-related diseases in adulthood. The objective of this study was to investigate the effectiveness of a healthy lifestyle intervention-including physical activity (PA) and eating habits (EH)-among female students in Jizan City, southwest Kingdom of Saudi Arabia (KSA).

Methods: A representative sample of 565 school students aged 12-15 years was randomly selected from four schools in Jizan, KSA. The PA and EH were assessed using a validated selfadministered questionnaire. A pre-post quasi-experimental study was implemented in three phases.

Results: Following the intervention, the school children in the intervention groups showed a significant improvement in their $\mathrm{EH}$ and PA. These improvements were documented in increased physical walking measured by the number of students walking daily, the number of days walked, and the time spent on vigorous activities (54.11 \pm 54.89 to $63.24 \pm 76.16)$. Fruits and vegetables had a similar consumption frequency in both the intervention and control groups. The snacks were frequently consumed among intervention group with a significant increase in the mean number from $1.64 \pm 0.93$ to $1.96 \pm 1.13(p=0.000)$ and fast food were less frequently consumed among intervention group than the control group $(p=0.000)$. The prevalence of obesity in the intervention group was reduced from $16.3 \%$ to $12.9 \%$, while it was significantly increased from $17.6 \%$ to $19.0 \%$ in the control group ( $p=0.0148$ ). Weight decreased by $0.37 \mathrm{~kg}$ in the intervention group, while it increased by $0.07 \mathrm{~kg}$ in the control group, but with no statistically significant increase.

Conclusion: In conclusion, healthy lifestyle interventions can improve short- and long-term outcomes in school children. When examining the health benefits of healthy lifestyle, the importance of dietary and PA behaviors should be considered. 


\section{Introduction}

Unhealthy dietary habits and lifestyle among adolescents are considered as risk factors for nutrition-related diseases in adulthood [1]. A large body of evidence suggest that obesity has become a major public health problem in the Arab countries, creating a health and economic burden on the government of these countries' [2]. The profile of nutritional status among adolescents in the Arabian Gulf countries is characterized by the increase of obesity and overweight among them $[3,4]$

Many studies have been conducted in Saudi Arabia to evaluate the prevalence of overweight and obesity among Saudi children. Al-Dossary et al. reported that there is a variation in the prevalence of obesity and overweight among children from different geographical regions of the Kingdom [5]. The eastern and central regions in KSA have a higher prevalence of obesity and overweight than the southern regions [5]. The overall prevalence of overweight and obesity among children in Eastern province was $19.0 \%$ and $23.3 \%$, respectively [5]. Another study conducted in Riyadh found that the overall prevalence of overweight and obesity were higher among girls in the age group 10-14 years (14.4\% and 18\%, respectively) [6]. Besides, another study conducted in southwestern Saudi Arabia found that the prevalence of overweight and obesity among girls were $15.5 \%$ and $13.9 \%$, respectively [7].

Reducing childhood obesity requires effective lifestyle and behavioral interventions that target healthy eating and physical activity among the general child population $[8,9]$. Most public health interventions for overweight prevention in children and adolescents have been conducted through the schools [8-10]. Lifestyle programs are multi-factorial interventions that are designed for individuals or groups according to their risk factor status and the needs of the subjects. These include promoting healthy lifestyle habits, dietary counseling, physical exercise training, and behavioral change targets [11].

Studies addressing school-based interventions among children and adolescents in Jazan region are scarce, and most of them are cross-sectional studies measuring obesity and lifestyle patterns. The aim of this study was to assess the effectiveness of a healthy multicomponent lifestyle interventions among students at intermediate schools in Jazan city, Saudi Arabia. This school-based lifestyle intervention study was developed with a hope to reduce childhood obesity in Jizan, Saudi Arabia and to investigate whether this lifestyle intervention is able to reduce obesity risk and increase healthy behaviors and knowledge of the pupils.

\section{Materials and Methods}




\subsection{Study design and subjects}

A pre-post quasi-experimental study was implemented among the female students aged 12-15 years of intermediate schools (grades 7-9) in Jazan city, Kingdom of Saudi Arabia (KSA).

\subsection{Sampling procedures}

The population included all female students among all schools belonging to the education office of the Jazan General Administration of Education, Ministry of Education. Four schools were randomly chosen according to the desired sample size. First two schools were non-randomly allocated to the intervention group, and the other two were allocated to the control group. Participants were recruited from each school voluntarily after a full description of study, then they were filtered by the study's inclusion and exclusion criteria. Eligible participants were recruited by a simple randomization method proportional to the number of students per school. Finally, the eligible chosen participants were asked to sign informed consent forms before data collection. The sample size was calculated using a $95 \%$ confidence level and $80 \%$ power of the study, the assumed reduction of obesity from $8 \%$ to $4 \%$ following intervention, which is taken as $\mathrm{P} 1$ and $\mathrm{P} 2$. The minimum sample size required for the present study after accounting for $15 \%$ dropout rate was 713 participants for both the intervention and control groups. The sampling frame of schools was obtained from the Ministry of Education in Jazan.

\subsection{Study phases and intervention strategies}

The following three phases were implemented among the schools selected as the intervention group: (i) base-line survey; (ii) intervention; and (iii) evaluation (post-survey) phases.

(i) Base-line survey phase: This was conducted amongst the students of the selected schools, with an aim to assess their healthy lifestyle patterns using the same tools, namely, questionnaire and anthropometric measurements. Each student who agreed to participate was interviewed first to collect sociodemographic data using a pre-tested, structured, close-ended questionnaire (following the stepwise approach to surveillance STEPS procedure) [12].

Questionnaires were administered in the classroom with the assistance of a class teacher to collect information on students' sociodemographic characteristics such as age, sex, and socioeconomic status; behavioral risk factors such as dietary patterns 
and physical activity; as well as family history of chronic diseases. Then, the student's anthropometric measurements were measured and recorded.

(ii) Intervention phase: This phase started in the two selected intervention schools for all students. The main goal of the intervention was based on promotion of healthy lifestyle patterns such as weight reduction, decreased consumption of fat, increased consumption of fruits and vegetable, and increased exercise. It focuses on the promotion of physical education classes per week; additional sport and play activities outside school hours; counseling sessions by the team and classroom education on healthy eating behavior; and active living and healthy lifestyle choices [11].

The intervention strategies were as follows:

1. One-day counseling session: The objectives of this session were:

- to convey knowledge to all students as well as teachers

- to influence attitudes and behaviors of students

- to assess knowledge and practice toward their healthy lifestyle

- the session included lectures, open discussions, role-playing, games, and questions

2. Health education classes: Following the strategies for healthy eating and physical activity within existing curriculum using classroom teachers for all students.

3. Morning session before class (Taboor): practice exercise.

4. Messages and material for the parents: mainly for those at risk to confirm their participation and collaboration

5. Individual intervention plan for overweight and obese students

(iii) Evaluation phase: Post-study survey was conducted for all schools to evaluate the effectiveness of intervention program on changing or promoting healthy lifestyle patterns among the students. Data were analyzed and used to compare and study the differences between the outcomes in the intervention and control schools.

For control schools, both pre- and post-study surveys were conducted.

\subsection{Study instruments}

For the purpose of the study, the World Health Organization (WHO) STEPS was used [12]. It covers three different levels of steps of risk factor assessment. These steps include: questionnaire (basic demographic information and behavioral risk factors) (STEP-1); 
physical measurements (STEP-2); and biochemical measurements (STEP-3). For the purpose of the study, we used STEPS 1 and 2.

(STEP - 1): Questionnaire included the following:

A. Basic demographic information: collection of information on demographic variables, such as age, sex, race/ethnicity, and socioeconomic status.

B. Behavioral risk factors: dietary patterns, physical activity.

(STEP - 2): Physical measurements: Obtaining anthropometric measurements such as weight, height after completion of the questionnaire, using standardized protocols and instruments.

Anthropometric measurements were taken using standardized techniques and calibrated equipment. Subjects were weighed to the nearest $0.1 \mathrm{~kg}$ in light indoor clothing and with bare feet or stockings. Height was measured without shoes and recorded to the nearest $0.5 \mathrm{~cm}$ using detecto weighing scale [13]. Scales were calibrated and checked daily.

Body Mass Index (BMI) was calculated as weight ( $\mathrm{kg}$ ) divided by the height squared $\left(\mathrm{m}^{2}\right)$ and then compared with the reference charts developed by the Center for Disease Control and Prevention [14]. BMI is a measurement standard used to determine childhood overweight and obesity. Overweight is defined as a BMI at or above the 85th percentile and below the 95th percentile for children and teens of same age and sex. Obesity is defined as a BMI at or above the 95th percentile for children and teens of same age and gender [14].

\subsection{Statistical analysis}

Epi Info version 3.2.2 software (Centers for Disease Control and Prevention (CDC), https://www.cdc.gov/epiinfo/index.html) was used to capture the data and SPSS version 17 (SPSS Inc., Chicago, IL, USA) was used for data analysis. Continuous variables were expressed as mean \pm SD (standard deviation) and 95\% confidence intervals (95\% $\mathrm{Cl}$ ). Categorical variables were expressed as median or percentages. The difference between the control and intervention groups was calculated using the two-sample mean-comparison test or Pearson's Chi-square test, depending on the kinds of variables. Each child's BMI $\left(\mathrm{kg} / \mathrm{m}^{2}\right)$ was calculated using the weight and height data. Prevalence rates were given in percentages. All $p$-values were two-tailed and considered significant when $<0.05$. 


\subsection{Ethical approval}

The study proposal, instruments, and tools were approved by the Medical Research Ethics Committee, Medical Research Center, Jazan University (project no. 3053). All participants, including the guardians on behalf of minors/children participants, who were involved in this study read, understood, and signed a written consent form. Permission was taken from school's administration. All records were kept confidential.

\section{Results}

Of the 713 initially eligible participants, 565 (79.2\%) completed the survey. The main reasons for the non-response was that students were sick or absent on the survey day. The mean age of the intervention group was $15.27 \pm 1.07$ years compared to $14.68 \pm$ 0.95 years for the control group. The mean age of all students in both groups was 15.4 \pm 1.06 years. As observed in Table 1, the majority of sampled participants (63.4\%) live in urban settings. The table further suggested that there are no significant differences in the distribution of most background characteristics for both the intervention and control groups except for the mode of living.

Table 2 shows that there was no significant difference in the mean of eating fruits and vegetables for both the intervention and control groups. It was also noticed that there was a significant increase in the mean number of snacks between meals from $1.64 \pm$ 0.93 to $1.96 \pm 1.13(p=0.000)$ in the intervention group. As shown in the table, the mean number of meals taken per day was increased from $2.49 \pm 0.84$ at baseline to 2.56 \pm 0.96 in the intervention group; however, they were not statistically significant. Also, there was a remarkable increase in habitual water drinking (for all $p<0.05$ ). Statistically significantly reduction was seen in the intervention group than in the control group in the mean number of days fast foods were eaten per week from $6.35 \pm 1.77$ to $5.74 \pm$ $1.95(p=0.000)$. Moreover, there was a reduction in drinking soft drinks per week after the intervention contrary to no significant change in the control group.

As presented in Table 3, there was a significant increase in the percentage of students who were walking at least 10 min a day from $49 \%$ to $61.2 \%$ compared to the control group, where there was no significant difference observed. The mean number of days walking for $10 \mathrm{~min}$ increased from $1.69 \pm 2.30$ to $5.30 \pm 2.23$ after the intervention $(p=$ 0.0000 ). Additionally, there was an increase in the mean of time doing moderate activity (walking or bicycling for travel) from $35.66 \pm 35.04$ to $47.19 \pm 49.24$ over time during the intervention with statistically significant increase $(p=0.02)$. This is in contrast to the control group where there was a reduction in the meantime from $52.07 \pm 66.64$ to 
TABLE 1: Background characteristics of the study population

\begin{tabular}{|c|c|c|c|c|}
\hline Characteristics & Intervention & Control & Total & P-value \\
\hline \multicolumn{4}{|l|}{ Mode of living: } & \multirow{3}{*}{0.013} \\
\hline Rural & $114(32.7)$ & $93(43.1)$ & 207 (36.6) & \\
\hline Urban & $235(67.3)$ & $123(56.9)$ & $358(63.4)$ & \\
\hline \multicolumn{4}{|l|}{ Parental status: } & \multirow{5}{*}{0.750} \\
\hline Live together & $319(91.4)$ & $198(91.7)$ & $517(91.5)$ & \\
\hline Divorced & $5(1.4)$ & $5(2.3)$ & $10(1.8)$ & \\
\hline Separated & $6(1.7)$ & $2(.9)$ & $8(1.4)$ & \\
\hline Widowed & $19(5.5)$ & $11(5.1)$ & $30(5.3)$ & \\
\hline \multicolumn{4}{|c|}{ Father's education status: } & \multirow{8}{*}{0.372} \\
\hline Illiterate & $11(3.2)$ & $5(2.3)$ & $16(2.8)$ & \\
\hline Read and write & $7(2.0)$ & $2(.9)$ & 9 (1.6) & \\
\hline Primary & $28(8.0)$ & $13(6.0)$ & $41(7.3)$ & \\
\hline Intermediate & $39(11.2)$ & $23(10.6)$ & $62(11.0)$ & \\
\hline Secondary & 69 (19.8) & $47(21.8)$ & $116(20.5)$ & \\
\hline $\begin{array}{l}\text { University \& post } \\
\text { graduate }\end{array}$ & $126(36.1)$ & $70(32.4)$ & $196(34.7)$ & \\
\hline Don't know & 69 (19.7) & $56(26.0)$ & $125(22.1)$ & \\
\hline \multicolumn{4}{|l|}{ Mother's education } & \multirow{8}{*}{0.480} \\
\hline Illiterate & 46 )13.2) & $16(7.4)$ & $62(11.0)$ & \\
\hline Read and write & $8(2.3)$ & $4(1.9)$ & $12(2.1)$ & \\
\hline Primary & 59 (16.9) & 43 (19.9) & 102 (18.1) & \\
\hline Intermediate & $62(17.8)$ & 33 (15.3) & 95 (16.8) & \\
\hline Secondary & 59 (16.9) & 37 (17.1) & 96 (17.0) & \\
\hline $\begin{array}{l}\text { University \& post } \\
\text { graduate }\end{array}$ & $83(23.7)$ & 56 (25.9) & 139 (24.6) & \\
\hline Don't know & $32(9.2)$ & $27(12.5)$ & $59(10.4)$ & \\
\hline $\begin{array}{l}\text { Descriptive measures } \\
\text { Mean } \pm \text { (SD) }\end{array}$ & 349 (100) & $216(100)$ & $565(100)$ & \\
\hline Age (years) & $15.27 \pm 1.07$ & $14.68 \pm 0.95$ & $15.4 \pm 1.06$ & 0.000 \\
\hline Hight (cm) & $150.5 \pm 6.6$ & $150.3 \pm 6.3$ & $150.4 \pm 6.5$ & 0.800 \\
\hline Weight (kg) & $48.9 \pm 13.3$ & $48.3 \pm 13.7$ & $48.7 \pm 13.4$ & 0.586 \\
\hline BMI & $21.5 \pm 5.2$ & $21.3 \pm 5.7$ & $21.47 \pm 5.4$ & 0.691 \\
\hline Total & 349 (100) & $216(100)$ & $565(100)$ & \\
\hline
\end{tabular}

$35.07 \pm 36.17$. In the intervention group, the mean time spent doing vigorous-intensity activities was increased from $54.11 \pm 54.89$ to $63.24 \pm 76.16$ with no statistical significant difference.

Figure 1 as well as Table 3 show that the prevalence of obesity among students in the intervention group was reduced from $16.3 \%$ at baseline to $12.9 \%$ but with no change in the number of overweight students. On the other hand, Figure 2 and the Table 4 
TABLE 2: Comparisons between intervention and control groups on the nutritional habits

\begin{tabular}{|l|l|l|l|l|l|l|}
\hline & \multicolumn{3}{|c|}{ Intervention group } & \multicolumn{3}{c}{ Control group } \\
\hline & $\begin{array}{c}\text { Pre Mean } \pm \\
\text { SD }\end{array}$ & $\begin{array}{c}\text { Post Mean } \\
\text { SD }\end{array}$ & P-value & $\begin{array}{c}\text { Pre Mean } \pm \\
\text { SD }\end{array}$ & $\begin{array}{c}\text { Post Mean } \pm \\
\text { SD }\end{array}$ & P-value \\
\hline $\begin{array}{l}\text { Fruit intake per } \\
\text { week (number of } \\
\text { days) }\end{array}$ & $2.25 \pm 2.02$ & $2.13 \pm 1.80$ & 0.336 & $2.33 \pm 2.25$ & $2.64 \pm 2.11$ & 0.182 \\
\hline $\begin{array}{l}\text { Number of meals } \\
\text { per day }\end{array}$ & $2.49 \pm 0.84$ & $2.56 \pm 0.96$ & 0.296 & $2.46 \pm 0.84$ & $2.61 \pm 1.10$ & 0.091 \\
\hline $\begin{array}{l}\text { Number of snacks } \\
\text { between meals }\end{array}$ & $1.64 \pm 0.93$ & $1.96 \pm 1.13$ & 0.000 & $1.65 \pm 0.924$ & $1.88 \pm 1.05$ & 0.006 \\
\hline $\begin{array}{l}\text { Fast food intake per } \\
\text { week }\end{array}$ & $6.35 \pm 1.77$ & $5.74 \pm 1.95$ & 0.000 & $6.13 \pm 1.86$ & $5.88 \pm 1.98$ & 0.143 \\
\hline $\begin{array}{l}\text { Number of water } \\
\text { cups per day }\end{array}$ & $3.28 \pm 1.98$ & $4.21 \pm 2.86$ & 0.000 & $3.32 \pm 2.18$ & $4.10 \pm 2.49$ & 0.001 \\
\hline $\begin{array}{l}\text { Bread intake per } \\
\text { week }\end{array}$ & $2.53 \pm 2.30$ & $2.07 \pm 2.03$ & 0.012 & $2.31 \pm 2.10$ & $2.33 \pm 2.23$ & 0.932 \\
\hline $\begin{array}{l}\text { Soft drinks per } \\
\text { week }\end{array}$ & $4.03 \pm 2.44$ & $3.77 \pm 2.30$ & 0.094 & $4.12 \pm 2.42$ & $4.15 \pm 2.47$ & 0.876 \\
\hline $\begin{array}{l}\text { Number of fish } \\
\text { rations per day }\end{array}$ & $0.84 \pm 0.62$ & $0.96 \pm 0.78$ & 0.027 & $0.90 \pm 50$ & $0.91 \pm 0.79$ & 0.827 \\
\hline
\end{tabular}

TABLE 3: Comparisons between the intervention and control groups on the physical activity habits

\begin{tabular}{|c|c|c|c|c|c|c|}
\hline \multirow[t]{2}{*}{ Variable } & \multicolumn{3}{|c|}{ Intervention group } & \multicolumn{3}{|c|}{ Control group } \\
\hline & Pre & Post & P-value & Pre & Post & P-value \\
\hline \multicolumn{7}{|c|}{ Walk for at least $10 \mathrm{~min}$ : } \\
\hline Yes & $171(49.0)$ & $215(61.2)$ & 0.001 & $139(64.4)$ & $144(66.7)$ & \multirow{2}{*}{0.687} \\
\hline No & $178(51.0)$ & $134(38.4)$ & & $77(35.6)$ & $72(33.3)$ & \\
\hline \multirow[t]{2}{*}{ Factor } & \multicolumn{3}{|c|}{ Intervention group } & \multicolumn{3}{|c|}{ Control group } \\
\hline & $\begin{array}{l}\text { Pre Mean } \pm \\
\text { SD }\end{array}$ & $\begin{array}{l}\text { Post Mean } \pm \\
\text { SD }\end{array}$ & P-value & $\begin{array}{l}\text { Pre Mean } \pm \\
\text { SD }\end{array}$ & $\begin{array}{l}\text { Post Mean } \pm \\
\text { SD }\end{array}$ & P-value \\
\hline $\begin{array}{l}\text { Days walked for } \\
\text { at least } 10 \mathrm{~min} \\
\text { continuously }\end{array}$ & $1.69 \pm 2.30$ & $5.30 \pm 2.23$ & 0.000 & $2.57 \pm 2.54$ & $5.45 \pm 1.98$ & 0.000 \\
\hline $\begin{array}{l}\text { Time spent } \\
\text { walking or biking } \\
\text { for travel on a } \\
\text { typical day }\end{array}$ & $35.67 \pm 35.03$ & $47.19 \pm 49.24$ & 0.024 & $52.07 \pm 66.64$ & $35.07 \pm 36.17$ & 0.022 \\
\hline $\begin{array}{l}\text { Time spent doing } \\
\text { vigorous-intensity } \\
\text { sports on a typical } \\
\text { day }\end{array}$ & $54.11 \pm 54.89$ & $63.24 \pm 76.16$ & 0.297 & $57.53 \pm 48.76$ & $79.11 \pm 86.27$ & 0.045 \\
\hline Weight $(\mathrm{kg})$ & $48.91 \pm 13.28$ & $48.83 \pm 14.29$ & 0.939 & $48.27 \pm 13.70$ & $48.35 \pm 14.66$ & 0.953 \\
\hline
\end{tabular}

illustrate a significant increase in the prevalence of obesity among students in control group from $17.6 \%$ to $19.0 \%$. $(p=0.01484)$. 


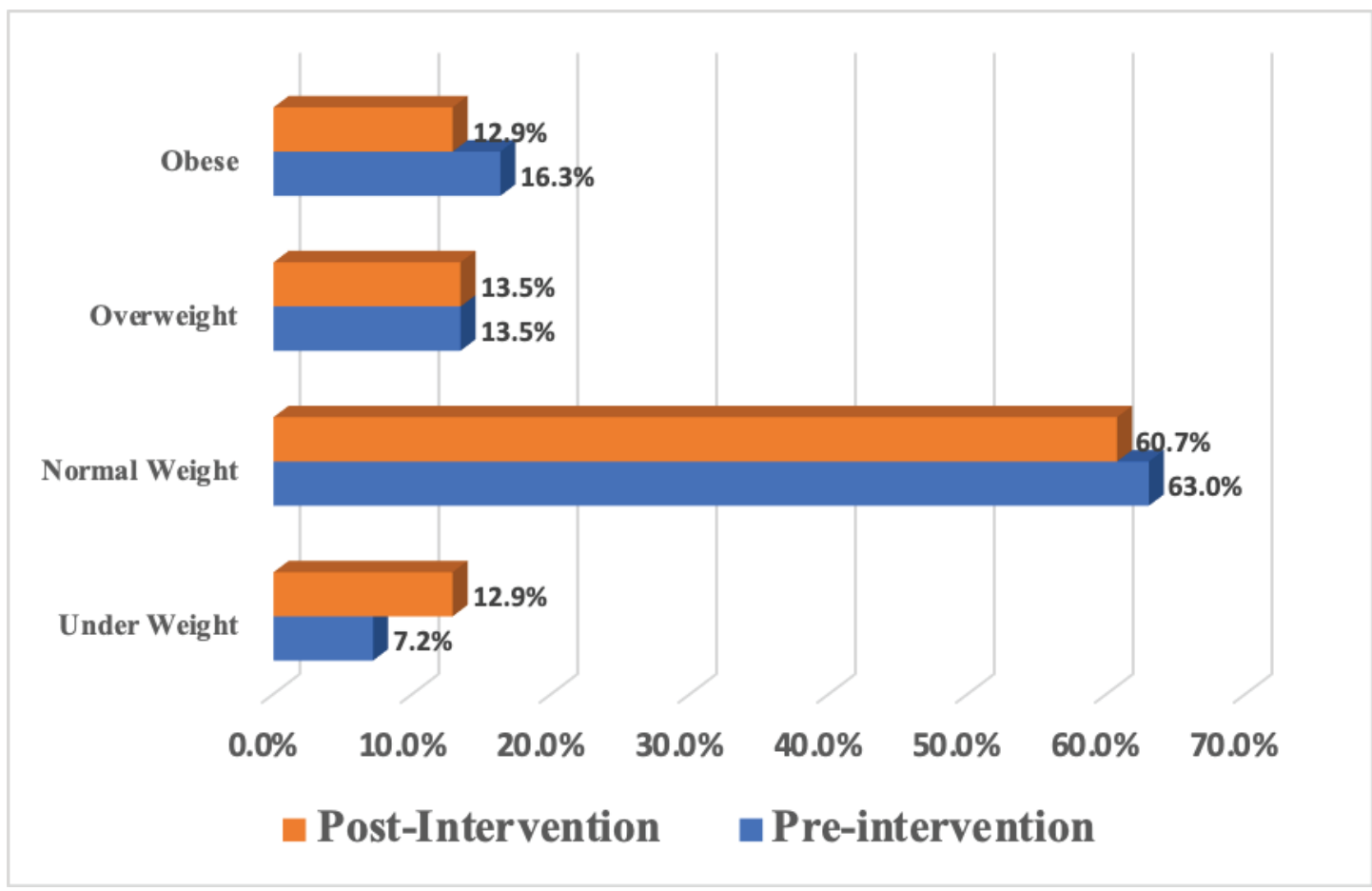

Figure 1: Impact of intervention program on BMI among the intervention group

TABLE 4: Comparisons between the intervention and control groups on BMl categories pre- and postintervention program

BMI category
Under Weight ( $<5 \%$ ile)
Normal Weight ( $5 \%-85 \%$ ile)
Over Weight ( $85 \%-95 \%$ ile)
Obese (>95\%ile)

\section{Discussion}

\begin{tabular}{|c|c|c|c|c|c|}
\hline \multicolumn{2}{|c|}{ Intervention group } & P-value & \multicolumn{2}{|c|}{ Control group } & P-value \\
\hline Pre N\% & Post N\% & & Pre N\% & Post N\% & \\
\hline $25(7.2)$ & $45(12.9)$ & & $16(7.4)$ & $37(17.1)$ & \\
\hline $220(63.0)$ & $212(60.7)$ & 0.06365 & $142(65.7)$ & $119(55.1)$ & 0.01484 \\
\hline $47(13.5)$ & $47(13.5)$ & & $20(9.3)$ & $19(8.8)$ & \\
\hline $57(16.3)$ & $45(12.9)$ & & $38(17.6)$ & $41(19.0)$ & \\
\hline
\end{tabular}

The purpose of this study was to assess the effect of a school-based lifestyle intervention program on some nutritional and physical activity habits as well as weight change among the female students in the intermediate schools in Jazan. Accumulated evidences suggest that the effect of school-based lifestyle interventions on obesity did not reach a consistent conclusion $[15,16]$.

In this study, a longitudinal analysis showed that over the six months period, the prevalence of obesity among students in the intervention group reduced from $16.3 \%$ at baseline to $12.9 \%$, but with no change in the percentage of overweight students. For the control group, there was no significant increase (from 17.6\% to 19.0\%) in the prevalence of obesity. These findings indicate that school-based interventions targeting obesity prevention can have positive and fruitful effects on student's anthropometric measures. 


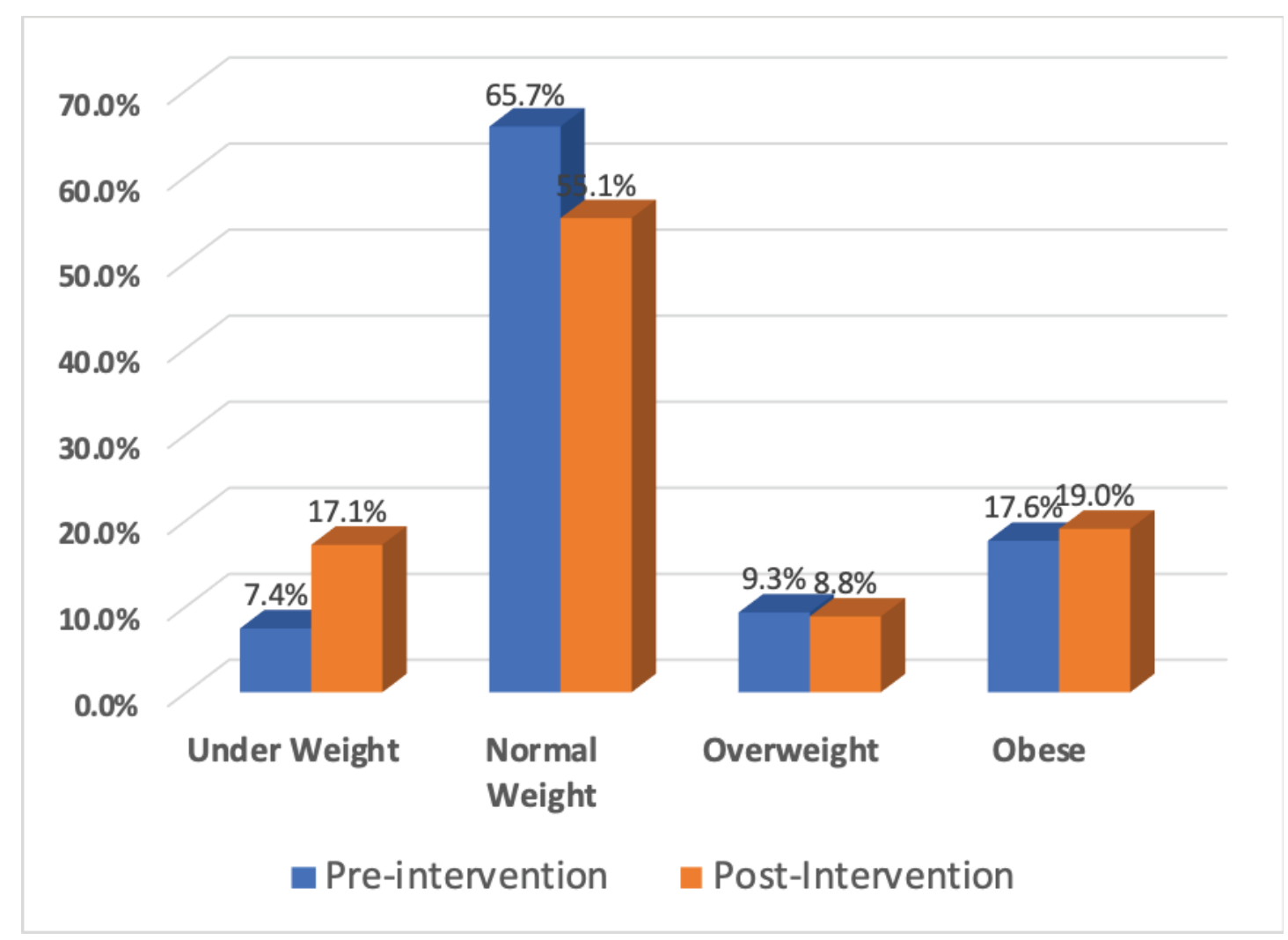

Figure 2: BMI among the control group pre- and post-intervention

Schools have been suggested as the ideal place to implement obesity prevention programs, in reducing the prevalence of overweight and obesity $[17,18]$.

Most published school-based interventions reported statistically significant beneficial effects compared with the control in at least some of the body-weight-related indices. In the present study, the students weight decreased by $0.37 \mathrm{~kg}$ in the intervention group, compared to an increase of $0.07 \mathrm{~kg}$ in the control group. This finding is in contrast with another study conducted for short time period of intervention where there was no significant change in the weight and BMI generally [18].

Changes in the behavior of students toward physical activity showed statistically significant increases in the percentage of students walking at least 10 mins a day from $49 \%$ to $61.2 \%$, compared to no change in the control group. Additionally, the mean number of days walking $10 \mathrm{~min}$ increased from $1.69 \pm 2.30$ to $5.30 \pm 2.23$ after the intervention.

There was a statistically significant increase in the mean of time doing moderate activity (walking or bicycling for travel) from $35.66 \pm 35.04$ to $47.19 \pm 49.24$ over time during the intervention. This is in contrast to the control group where there was a reduction in the meantime from $52.07 \pm 66.64$ to $35.07 \pm 36.17$. This is in line with 
the study conducted in the United Arab Emirates (UAE), where there was a remarkable decrease in the estimated physical inactivity among females [19].

In the intervention group, the mean time spent doing vigorous-intensity activities was increased from $54.11 \pm 54.89$ to $63.24 \pm 76.16$, but with no significant increase. Internationally, the Global School Based Student Health Survey, conducted in 2010, showed that among 34 countries, only $24 \%$ of male and $15 \%$ of female school children met the recommendations of 60 min of moderate-to-vigorous physical activity per day [20].

Significant reduction was seen in the intervention than in the control in the mean number of days eating fast foods per week. Moreover, $4.1 \%$ of the students in the intervention group had restricted their frequency of intake of fast foods per week. Additionally, there was reduction in drinking soft drinks per week after intervention contrary to no significant change in the control group. This change could be attributed to the role of school administration and support of parents regarding the side effects of drinking soft drinks and eating fast foods. Other studies have also resulted in a significant restriction (16.3\%) of the frequency of fast food intake among students. Fruits and vegetables are important components of a healthy diet. Low fruit and vegetable consumption and high saturated fat intake are linked to poor health and increased risk of non-communicable diseases [21,22]. An estimated 5.2 million deaths worldwide were attributable to inadequate fruit and vegetable consumption in 2013 [22].

The strength of this study is that it is relatively easy to replicate. Despite this strength, the study has some limitations. First, the lack of random assignment is a major weakness of this quasi-experimental study, the randomization was conducted at school level, not at student level. Second, the study participants were aware of the experiment and might have changed their behavior and this in turn may have affected the internal validity of the study. Finally, the limited time frame, as we were not able to do follow-up the students for more than six months.

\section{Conclusion}

In conclusion, the school children in the intervention group showed improvements in eating habits $(\mathrm{EH})$, and physical activity (PA). These improvements were manifested in increased physical walking measured by the number of physical steps per week, daily snacks and less fast food consumption and the daily quantity of water ingested. While their nutrition/physical activity knowledge significantly increased, their BMI significantly decreased. When examining the health benefits of healthy lifestyle, the importance 
of dietary and PA behaviors should be considered. We recommend healthy lifestyle program to be integrated in the Jizan school health programs.

\section{Acknowledgments}

The authors gratefully acknowledge the students who consented to participate in the study, the leaders of the schools that served as data collection sites, and the directorate of the Jazan General Administration of Education, Ministry of Education. They also acknowledge students and colleagues at Jazan University Clinical Nutrition Department who kindly assisted in the research activities, and Jazan University Deanship of Scientific Research for funding the study. A special thanks to Mrs. Sawda Osman for her contribution in data entry.

\section{Conflict of Interest}

None declared.

\section{Author Contributions}

FAEE is the chief investigator of the project. HEEK, AMG, MEM, and IAB contributed to the development and implementation of the project. All authors and MSM contributed to the drafting of this manuscript and approved the final version of the manuscript for publication.

\section{References}

[1] WHO. (2003). Diet, Nutrition and the Prevention of Chronic Diseases. Report of a Joint WHO/FAO Expert Consultation (WHO Technical Report Series 916). Geneva: World Health Organization.

[2] Musaiger, A.O., et al. (2011). Strategy to combat obesity and to promote physical activity in Arab countries. Diabetes, Metabolic Syndrome and Obesity: Targets and Therapy, vol. 4, pp. 89-97.

[3] AlBlooshi, A., et al. (2016). Increasing obesity rates in school children in United Arab Emirates. Obesity Science \& Practice, vol. 2, issue 2, pp. 196-202.

[4] Ng, S.W., et al. (2011). The prevalence and trends of overweight, obesity and nutritionrelated non-communicable diseases in the Arabian Gulf States. Obesity Reviews, vol. 12, issue 1, pp. 1-3. 
[5] Al Dossary, S.S., et al. (2010). Obesity in Saudi children: a dangerous reality. Eastern Mediterranean Health Journal, vol. 16, issue 9, pp. 1003-1008.

[6] Al Saleh, A. (2015). Prevalence's of overweight and obesity among Saudi Children. International Journal of Science and Research, vol. 4, pp. 765-769.

[7] Kaufman-Shriqui, V., et al. (2016). Effect of a school-based intervention on nutritional knowledge and habits of low-socioeconomic school children in Israel: a clusterrandomized controlled trial. Nutrients, vol. 8, issue 4, p. 234.

[8] Xu, F., et al. (2015). Effectiveness of a randomized controlled lifestyle intervention to prevent obesity among Chinese primary school students: CLICK-obesity study. PLOS ONE, vol. 10, issue 10, e0141421.

[9] Xu, F., et al. (2014). A school-based comprehensive lifestyle intervention among Chinese kids against obesity (CLICK-Obesity): rationale, design and methodology of a randomized controlled trial in Nanjing city, China. BMC Public Health, vol. 12, issue 1, p. 316.

[10] Boyle, M.A. (2003). Community Nutrition in Action: An Entrepreneurial Approach (3rd ed.). Bellmont, Calif: Wadsworth.

[11] Sabharwal, M. (2015). Effectiveness of lifestyle interventions among college students: an overview. Journal of Nutrition \& Food Sciences, vol. 5, issue 3.

[12] World Health Organization. STEPS Instrument for NCD Risk Factors (Core and Expanded Version 1.4) The WHO STEP wise approach to Surveillance of noncommunicable diseases (STEPS) EXAMPLE-for a current smoker who eats 8 servings of fruit on a typical day [Internet]. [cited 2017 Jun 13]. Retrieved from: http://apps.who.int/iris/bitstream/handle/10665/68346/WHO_NMH_CCS_03. 03.pdf?sequence=1

[13] Scales Galore. S. Detecto - 6439 Digital Eye-Level Physician Scale - height rod [Internet]. [cited 2017 Dec 30]. Available from: http://www.scalesgalore.com/d6439. $\mathrm{cfm}$ ?

[14] Kuczmarski, R.J., et al. (2002). 2000 CDC growth charts for the United States: methods and development. Vital and Health Statistics, issue 246, pp. 1-190.

[15] Adab, P., et al. (2015). A cluster-randomized controlled trial to assess the effectiveness and cost-effectiveness of a childhood obesity prevention programme delivered through schools, targeting 6-7 year old children: the WAVES study protocol. BMC Public Health, vol. 15, issue 1, p. 488.

[16] Healy, G.N., et al. (2008). Objectively measured sedentary time, physical activity, and metabolic risk the Australian diabetes, obesity and lifestyle study (AusDiab). Diabetes Care, vol. 31, no. 2, pp. 369-371. 
[17] Ardic, A. and Erdogan, S. (2017). The effectiveness of the COPE healthy lifestyles TEEN program: a school-based intervention in middle school adolescents with 12 month follow-up. Journal of Advanced Nursing, vol. 73, issue. 6, pp. 1377-1389.

[18] Thakur, J. and Singh Thakur, J. (2015). Effect of 12-week lifestyle intervention on behavioral, anthropometry and biochemical profile of school children in Chandigarh, India. Journal of Community Medicine \& Health Education; vol. 5, issue 367, pp. 2161-0711.

[19] Gaffar, A.M. (2015). Nutrition-related chronic diseases epidemic in UAE: can we stand to STOP it? Sudanese Journal of Public Health, vol. 4, issue 4.

[20] World Health Organization. (2014). NCDs I Global school-based student health survey (GSHS) implementation. WHO. Retrieved from: http://www.who.int/ncds/surveillance/ gshs/country/en/

[21] Macera, C.A. (2003). Promoting healthy eating and physical activity for a healthier nation. Retrieved from: https://www.cdc.gov/healthyyouth/publications/pdf/pp-ch7. pdf

[22] World Health Organization. (2015). Increasing fruit and vegetable consumption to reduce the risk of non-communicable diseases (WHO technical report). Retrieved from: https://www.who.int/elena/titles/fruit_vegetables_ncds/en/ 